\title{
Perception of the concept of smart city from the perspective of cities and municipalities of the Slovak Republic
}

\author{
Katarina Repkova Stofkova ${ }^{1, *}$, and Patricia Janoskova ${ }^{1}$ \\ ${ }^{1}$ University of Zilina, Faculty of Operation and Economics of Transport and Communications, \\ Univerzitna 1, 01026 Zilina, Slovakia
}

\begin{abstract}
Research background: From time immemorial, settlements face various pitfalls and cope with a large number of problems on a daily basis. However, the 21 st century also brings new challenges related to globalization, climate change, demographic change and many others. One of the answers or efforts to solve these problems are smart cities. Smart City as a concept of strategic management is a tool that primarily uses modern technologies to improve the quality of life of residents of individual cities and municipalities. At the same time, there is a synergy of various activities, the no less significant result of which is the achievement of economic and socio-economic successes.

Purpose of the article: The main purpose is to evaluate the innovations of individual municipalities and cities within the Slovak Republic. The intention is to evaluate the level of implementation of innovative solutions of cities and municipalities, to find out awareness of the concept of smart city, used strategies, projects, factors, technologies, and other elements of smart city.

Methods: The theoretical part was processed using the method of analysis and synthesis. In the practical part, the primary research was used to determine the attitude of cities, which was carried out in the form of a questionnaire.

Findings \& Value added: Cities and municipalities expressed their attitude to implementation of concept of smart city, financial demands, return on investment and the importance of implementing the smart city concept in building a sustainable and competitive ecosystem.
\end{abstract}

Keywords: smart city; information and communication technologies; sustainability

JEL Classification: $O 14 ; O 18 ; R 11 ; R 58$

\footnotetext{
${ }^{*}$ Corresponding author: katarina.stofkova@fpedas.uniza.sk
} 


\section{Introduction}

Smart City as well as the Internet of Things (IoT) is not a futuristic vision of the future, but a current trend of cities and towns around the world. However, this issue is little known for cities and municipalities in the Slovak Republic. Smart City as a concept of strategic management is a tool that primarily uses modern technologies to improve the quality of life of residents of individual cities and municipalities. At the same time, there is a synergy of various activities, the no less significant result of which is the achievement of economic and socio-economic successes. (Yangbet al., 2021; Hornakova et al, 2020) With IoT technologies, which are part of smart infrastructure, cities and municipalities can more effectively manage the impact of people migrating to cities as a result of the urbanization trend. The Smart City concept emphasizes the balance between the so-called gray infrastructure, the built-up and priority functional part of the city, and the green infrastructure, which focuses on the efficient use of resources associated with the sustainability of the urban ecosystem. (Kumar, 2020)

Smart City can be characterized as a complex of individual technologies, the aim of which is to optimize activities within a predetermined location, city. Smart solutions in cities are based on the use of modern electrical, electronic, information and communication technologies (ICT), allowing residents easier access to information, creating conditions for more efficient use of energy resources, helping to achieve better transport solutions, better health care, increase safety, they support education, enabling cities to build a better functioning society. (Kirimtat, 2020)

The Swiss academic institute - Institute for Management Development (IMD) defines the term Smart City as: „An urban area that has become more efficient and / or greener and / or more socially inclusive through digital technologies. The aim of Smart City is to increase its attractiveness to citizens and / or businesses by improving and / or adding city service. " (Sarv and Soe, 2021)

According to TWI, one of the world's leading independent research and technology organizations with expertise in Smart City and technical processes: „A smart city uses information and communication technologies to improve operational efficiency, share information with the public and provide better quality government services and the wellbeing of citizens. " (Zhang et al., 2021)

The Organization for Economic Co-operation and Development (OECD) defines smart cities as: „Initiatives or approaches that effectively use to improve citizens' well-being and digitize to provide more efficient, sustainable and inclusive urban services and the environment as part of multi-stakeholder cooperation. " (Ibrahim et al., 2020)

The Smart City concept therefore represents a comprehensive view of the city's infrastructure, while using innovative digital technologies it affects all functional areas of the city. The main goal in the long run is to save natural resources. After the introduction of the Smart City concept, cities and municipalities are becoming more attractive locations. However, the innovation of activities raises the question of the long-term sustainability of the set concept of a smart city. The time and financial demands are assessed. (Barah et al., 2021) The development and planning of the concept directly reflects the requirements of small and medium-sized enterprises in the area. At the same time, the involvement of the population must not be forgotten, and their participation is required, and it is appropriate to motivate them. Related to this is an increase in awareness, which results in active communication between individual entities, i.e. the city / municipality and the population. (Tran et al., 2020)

Due to the expansion of built-up areas, the urban environment threatens the relative size of green spaces in cities. Green spaces are attacked by the claims of investors with the intention of efficiency resulting from the progressive feature of Smart City. (Lazniewska et al., 2021) Thanks to the ecosystem services offered by greenery in cities, the interest of the 
population in eliminating air pollution is increasing. The importance of the balance between the so-called gray and green component of Smart City is also expressed by the growing interest of Smart City elements in the use of green areas of the city in order to prevent the consequences caused by weather fluctuations. These include torrential rain, drying of water sources, heat waves or raising the temperature of the atmosphere. Greenery helps retain rainwater and increase biodiversity. (Kaluarachchi, 2021; Diene et al., Magaia et al., 2021)

Green infrastructure prioritizes multifunctionality. This means that if the ecosystems of a given area are not damaged, they can be used multidimensionally using the various functions offered by the green infrastructure. (Song et al., 2021) The aim is to provide environmental, social and economic benefits. Green infrastructure also affects the quality of life, for example by reducing air pollutants or an adequate environment for relaxation and physical activity. The extent of the impact of the benefits of this structure depends on the application and maintenance of the infrastructure. (Gao et al., 2021)

Green infrastructure is less costly than conventional gray. It provides green jobs and reduces the consumption of natural resources. Healthcare costs are also reduced. At the community level, green infrastructure has been shown to reduce unemployment and support economic growth. In the locality of the given infrastructure, the value of real estate is an order of magnitude higher than in other parts of the city where this way of perceiving ecology is not applied. Residents and businesses are thus motivated to behave responsibly with respect for nature. (Song et al., 2021; What is a Smart City)

The Smart City concept implements various ICTs enabling cities and municipalities to integrate various intelligent strategies to collect and analyse the information obtained. This puts pressure on the development of the employee's work skills and on his ability to flexibly adapt to changing conditions. In order to function as a fully valued workforce, one must constantly expand one's abilities, knowledge, and skills. (Sukalova \& Stofkova,2020) Intelligent urban technologies allow urban infrastructure officials to communicate directly with the community of an area, while seeking to monitor what is happening in the city and how it is developing. (Smart Cities, 2020; Stofkova et al., 2016) ICTs are used to increase the quality, efficiency and interactivity of urban services, to reduce costs, resource consumption and, last but not least, to increase contact between citizens and the city / municipality. The Smart City concept integrates ICT and various physical devices connected to the IoT network to optimize the management efficiency of the Smart City concept. (IoT, 2019)

\section{Methodology}

The aim of this scientific article is to evaluate the innovations of individual municipalities and cities within the Slovak Republic, focusing on the level of implementation of innovative solutions of cities and municipalities in the Slovak Republic. The result of the research is a finding out the current state and degree of innovation of intelligent and IoT solutions within the concept of Smart City of selected cities and municipalities in the Slovak Republic.

The sources of the information used were obtained from secondary research, consisting of book and Internet sources, and primary research, carried out by means of an electronic inquiry, carried out electronically by means of a questionnaire in the Google Forms environment. The primary sources of information come from the responses of research respondents (cities and municipalities) randomly selected according to a specified representative research sample. (Kubas and Stofkova, 2017; Tomsik, 2017) The primary research was focused on individual cities and municipalities with a total of 2933. The minimum number of respondents was then calculated using the following formula: 


$$
n \geq \frac{N * t_{1-\frac{\alpha}{2}}^{2} * \sigma^{2}}{(N-1) * \Delta^{2}+t_{1-\frac{\alpha}{2}}^{2} * \sigma^{2}}
$$

where: $n=$ minimum sample size (minimum number of respondents); $t_{1-a / 2}=$ critical value determined from tables; $\sigma^{2}=$ variance calculated from the standard deviation; $\Delta=$ maximum permissible error range.

The calculation showed that at $95 \%$ confidence of the estimate and $5 \%$ of the maximum allowable margin of error, at least 247 responses had to be obtained from the respondents. Out of the addressed 2004 towns and municipalities of the Slovak Republic, 351 respondents successfully completed the questionnaire. The return rate of the questionnaire was at the level of $17.5 \%$.

\section{Results}

Through the set research goals and assumptions, it was found that out of the whole sample of 351 respondents, up to $67 \%$ of respondents have knowledge in the field of Smart City and the Internet of Things. Most respondents came from the Banska Bystrica self-governing region. Within the whole sample of 351 respondents, the average knowledge of the term Smart City is marked as sufficient to good. The average knowledge of the Internet of Things was sufficient.

Under the term Smart City, the most frequent respondents imagined the implementation of modern technologies in urban infrastructure, the expansion of modern technologies, increasing the living standards of citizens and new solutions in providing services to the city / municipality, which means that respondents have at least minimal knowledge of the issue.

Within the set of respondents who have knowledge in the field of the problem, up to $75 \%$ of respondents do not use intelligent solutions in their territory. The group of respondents that implements intelligent solutions within the city / municipality most often mentioned the use of intelligent public lighting, integrated parking system of public parking areas, camera and security systems, monitoring of energy consumption of public buildings and mobile applications for communication between city / municipality.

Of the group of 157 respondents who do not use intelligent solutions within their city / municipality, up to $54 \%$ of respondents are not interested in investing in solving this problem in the future (Fig. 1). The most numerous group were respondents from the Prešov self-governing region. The most common reason for this decision was the lack of financial resources of individual respondents. Within the group of respondents who are interested in investing in Smart City solutions in the future, they most often stated that this is an inevitable trend.

The most frequent respondents stated their interest in implementing an intelligent municipal waste collection system, while the payment for municipal waste will correspond to its quantity and weight. They also stated their interest in interactive communication systems between the city / municipality and citizens, energy-efficient public buildings, a system of intelligent lighting of public spaces and systems of effective management of the city / municipality. 


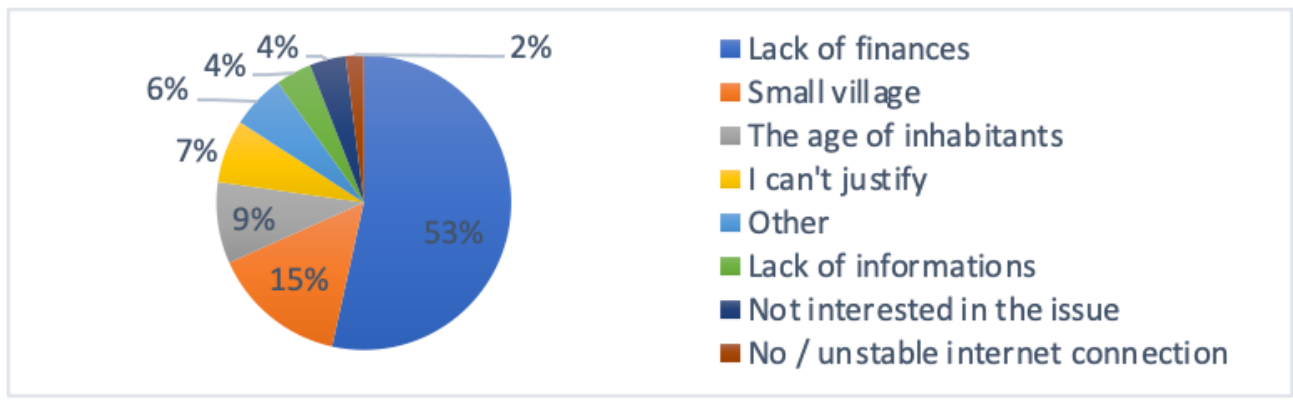

Fig. 1. Reasons for the lack of interest of cities and municipalities in the implementation of intelligent solutions.

Source: Own processing.

Within the whole sample of 351 respondents, $39 \%$ of respondents mentioned the awareness of the citizens of the city / municipality as the most important factor in the success of the Smart City concept of innovative management and 35\% of respondents. Regarding the usefulness of Smart City solutions, up to $77 \%$ of respondents stated that the solutions are not beneficial for their community, with the most common reason being the demographic aging of the population.

The knowledge of individual respondents within the intelligent technologies used in the territory of the Slovak Republic is shown in Fig. 2.

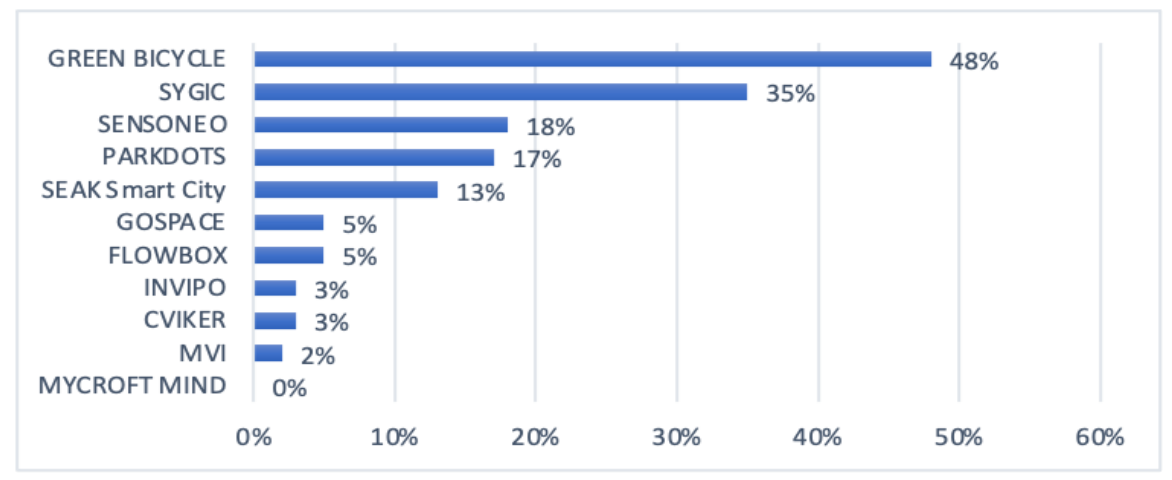

Fig. 2. Knowledge of individual technologies used in the Slovak Republic.

Source: Own processing.

From the surveyed sample of respondents, up to $48 \%$ of respondents knew the Smart City solution called Green Bicycle. The second most numerous group of answers was the SYGIC technological solution, which represented approximately $35 \%$. No one knew the solution called MYCROFT MIND in the sample.

Respondents applying Smart City solutions within their city / municipality most often financed projects (Fig. 3.) by a combination of their own and foreign sources, stating that the financing of innovative solutions is financially demanding. Through their own resources, projects were financed mainly by respondents with a population ranging from 1,000 to 4,999 . Respondents using exclusively foreign sources of funding most often reported a population ranging from 20,000 to 49,999 . their return. The most common benefits resulting from investing in innovative technologies were the respondents saw savings in city / municipality funds, streamlining communication between the city / municipality and citizens, motivating citizens and more efficient city administration. 


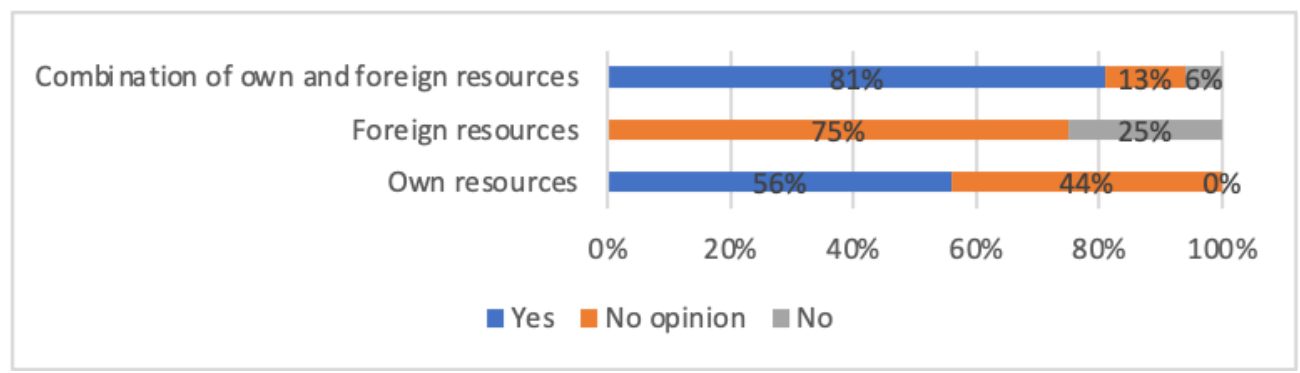

Fig. 3. Relationship between sources of financing and evaluation of financial demands of implementation of innovative technologies.

Source: Own processing.

Respondents see a lack of innovation in the field of infrastructure (Fig. 4), especially in terms of local sewerage (25\%). They are mainly interested in building a sewerage network and connections for individual households. The second area suffering from a lack of innovation is the energy intensity of public buildings, which have a negative impact on the city / municipal budget. The area of electricity distribution had the smallest relative share with a total share of $6 \%$.

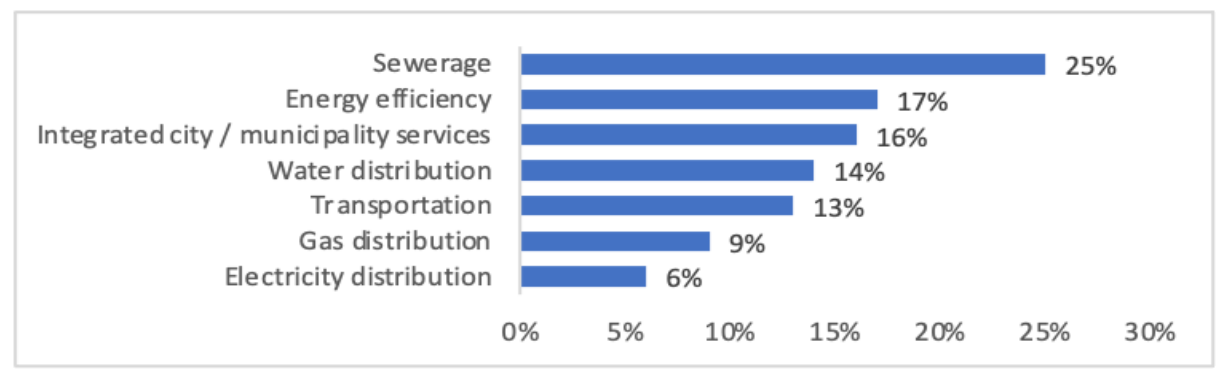

Fig. 4. Areas suffering from a lack of innovation.

Source: Own processing.

Respondents consider the Internet of Things technology to be the most important element of the Smart City concept, up to $68 \%$. It is followed by Open Data (18\%), Cloud Computing $(8 \%)$, Big Data $(5 \%)$ and the least important element of respondents is Blockchain (1\%). The answers of individual respondents are shown in Fig. 5.

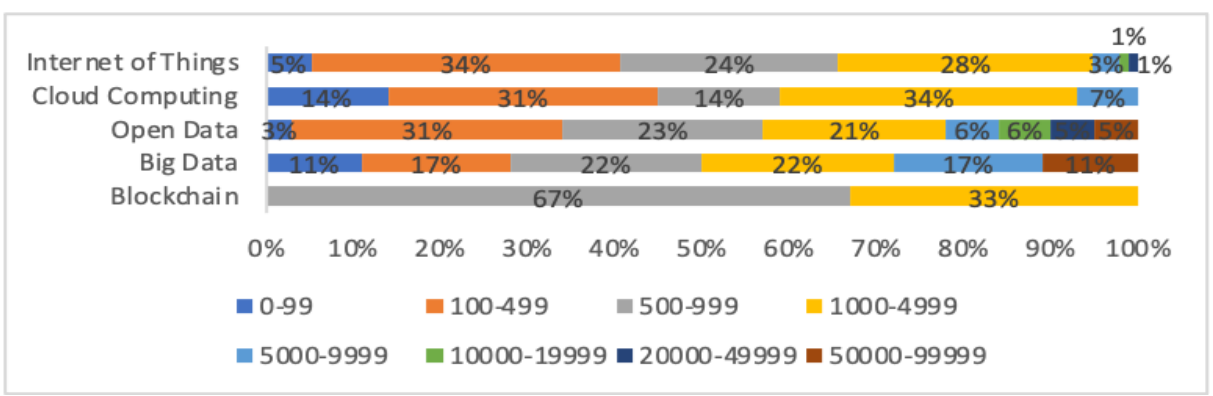

Fig. 5. Categorization of respondents according to the number of inhabitants in relation to the importance of the elements of Smart Cities.

Source: Own processing. 
The most numerous group that considers the Internet of Things to be the most important element are cities / municipalities with a population of 100 to 499 (34\%). The smallest group is cities / municipalities with a population of 10,000 to 19,999 , with this group representing approximately $1 \%$.

As the primary area of using the Internet of Things, more than $44 \%$ of respondents use it in the area of minimizing operating costs. The most numerous group that uses the Internet of Things in the area of minimizing operating costs are respondents from the Banska Bystrica and Zilina self-governing regions. Approximately $14 \%$ of respondents who use the Internet of Things said that technology has a high impact on the development of urban / municipal infrastructure, with the biggest benefit being time savings.

The aim was also to determine the degree of interest in the future implementation of the Internet of Things in the strategic document of the city / municipality of individual respondents. Only 60 respondents were processed, who indicated that they were interested in implementing the Internet of Things in the strategic document of the city / municipality, which represents approximately $19 \%$ of the total sample of 351 respondents. The planned time horizon for the implementation of the Internet of Things in the strategic document is shown in Fig. 6.

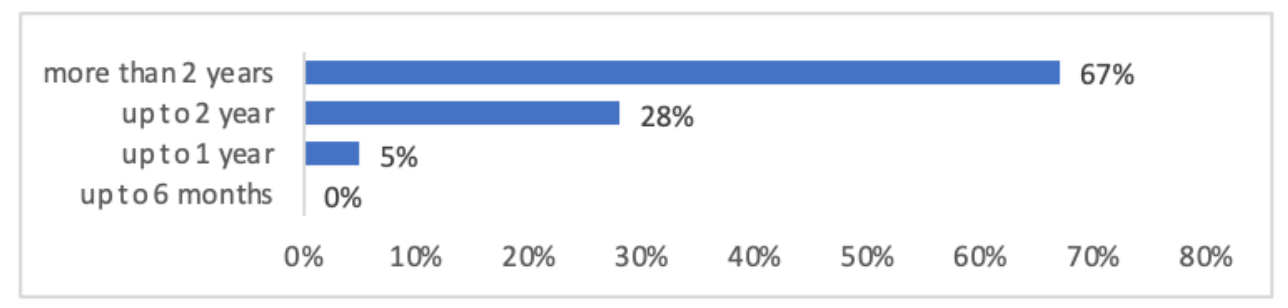

Fig. 6. Time horizon for the implementation of the Internet of Things in the Strategic Document of the city / municipality.

Source: Own processing.

Of the set of respondents who plan to implement the Internet of Things in the strategic document of the city / municipality, up to $67 \%$ of respondents stated a time horizon of more than 2 years. Not a single respondent mentioned the case of immediate implementation in terms of time within half a year.

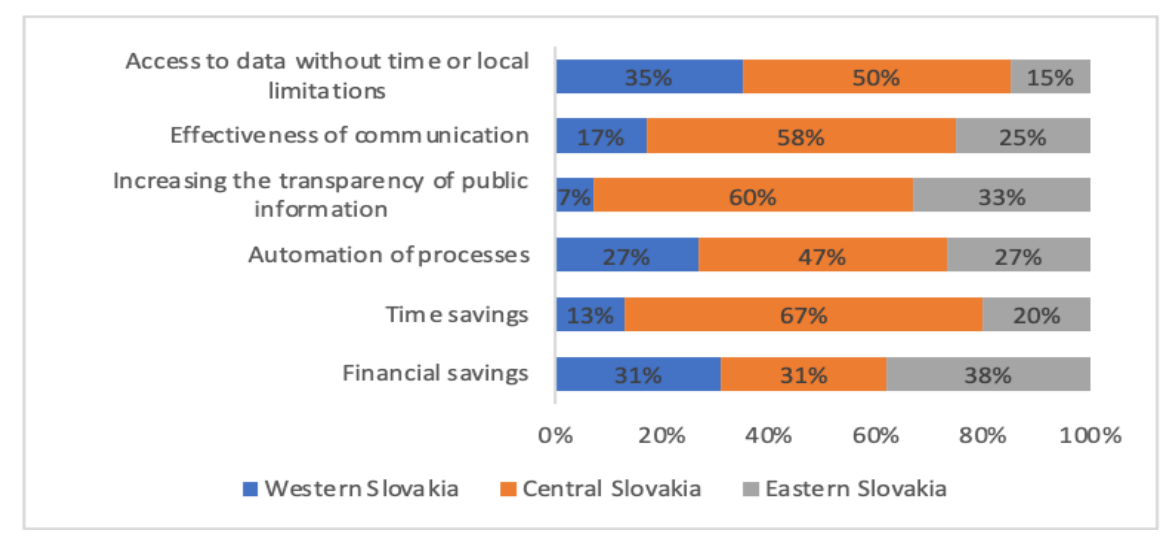

Fig. 7. Positive impact of the implementation of the Internet of Things.

Source: Own processing. 
As part of the comparison of individual areas that have a positive effect on the Internet of Things, the most frequent respondents mentioned the area of transparency of public information (Fig. 7). In relative terms, this set was about $19 \%$. However, according to the respondents, the Internet of Things affects the area of communication efficiency the least. Respondents from western Slovakia most often stated that the implementation of the Internet of Things has a positive impact on access to data without time and space restrictions. Respondents from central Slovakia stated that the Internet of Things has the most favourable effect on saving time. Respondents belonging to the territory of eastern Slovakia stated that the biggest benefit resulting from the implementation of the Internet of Things is financial savings.

As part of the issue of Green Infrastructure, up to $82 \%$ of respondents stated that Green Infrastructure belongs to the sphere of a modern city / municipality. In the subsequent analysis of individual respondents' knowledge in the field of Green Infrastructure, the respondents stated that it deals with ecology, improving the environment of the urban / municipal region, eliminating concrete areas, expanding green areas, promoting electromobility and reducing Carbon dioxide emissions overall.

The set of respondents who are interested in innovative technologies evaluates the relationship between citizens' awareness and innovative activities of the city / municipality on a scale from 1 (insignificant) to 5 (critically significant), mostly neutral to significant. Of the set of respondents on the issue of monitoring the development of technological innovations, approximately $60 \%$ of respondents stated that they monitor developments in Slovak or foreign cities / municipalities. Approximately $85 \%$ of respondents are interested in implementing intelligent solutions other than those used so far. These were mainly solutions for intelligent registration of municipal waste, reduction of energy intensity of public buildings with the help of renewable sources and solutions for intelligent public lighting. The analysis of the most widespread innovative solutions shows that the numerous solutions used include, for example, the Data Center of Municipalities and Cities (DCOM), WIFI for you or the Smart Cities Club.

\section{Conclusions}

Smart City and the Internet of Things are a necessary trend, whose extensive capabilities can be used not only for effective city management, but also for the continuous improvement of the quality of life of the inhabitants of towns and villages. The Smart City concept has a societal impact on all areas of urban / municipal infrastructure. The concept of Smart City and the Internet of Things form one unit, they are interconnected and indivisible, while the existence of the concept of Smart City is directly dependent on the way of application of individual elements of information and communication technologies.

The questionnaire research shows that cities and municipalities in the Slovak Republic have knowledge in the field of Smart City and the Internet of Things, while the concept of the Internet of Things is less well known. Despite their knowledge of the issue, most cities and municipalities do not implement intelligent solutions based on modern information and communication technologies in urban / municipal infrastructure, but cities and municipalities are aware of the importance and necessity of applying intelligent solutions to effective and modern city / municipality management.

The implementation of intelligent solutions is financially and personnel-intensive for many municipalities. Cities in this area are significantly helped by the possibilities of financing intelligent solutions through foreign financial sources and subsidies. Smaller municipalities in particular consider financial support from the state to be the starting point for Smart City development. 
The Smart City concept requires the complexity of cities and municipalities, while bringing a number of benefits. Thanks to effective management, cities and municipalities want to improve the functionality, sustainability and living standards of citizens. However, this requires the integration of innovative technologies, as the key element is the exchange and analysis of data between IoT devices. Through modern information and communication technologies, cities and municipalities are able to exchange data not only within a certain locality, but also with each other between individual cities / municipalities. Cities and municipalities using the Smart concept are therefore able to face the problems of an urbanized society more effectively.

\section{Acknowledgement}

This paper was supported by project KEGA 052ŽU-4/2021, VEGA 1/0518/19.

\section{References}

1. Barah, M., Khojandi, A., Li, XP., Hathaway, J. \& Omitaomu, O. (2021). Optimizing green infrastructure plaecemnt under precipitation uncertainty. OMEGA-International Journal of Management Science, 100.

2. Diene, B., Rodrigues, J.J., Diallo, O., Ndoye, E.M. \& Korotaev, V.V. (2020). Data management techniques for Internet of Things. Mechanical Systems and Signal Processing, 138.

3. Gao, X.H., Pishdad-Bozorgi, P., Shelden, D.R. \& Tang, S. (2021). Internet of Things Enabled Data Acquisition Framework for Smart Building Applications. Journal of Construction Engineering and Management, 147(2).

4. Hornakova, N., Caganova, D., Stofkova, J. et al. (2020). Industry 4.0 Future Prospects and Its Impact on Competencies. Lecture Notes in Mechanical Engineering, 73-84.

5. Ibrahim, A., Bartsch, K. \& Sharifi, E. (2020). Green infrastructure needs green governance: Lessons from Australia's largest integrated stormwater management project, the River Torrents Linear Park. Journal of Cleaner Production, 261.

6. Internet of Things - Brochure. (2019). European Commission. Retrieved from: https://ec.europa.eu/digital-single-market/en/news/internet- things-brochure.

7. Kaluarachchi, Y. (2021). Potential advantages in combining smart and green infrastructure over silo approaches for future cities. Frontiers of Engineering Management, 8(1), 98-108.

8. Kirimtat, A., Krejcar, O., Kertesz, A. \& Tasgetiren, M.F. (2020). Future Trends and Current State of Smart City Concepts: A Survey. IEEE ACCESS, 8, 86448-86467.

9. Kubas, J. \& Stofkova, Z. (2017). Application of Some Research Methods to Determine the Level of Safety in Municipalities. 7th International Conference on Intercultural Education - Education, Health and ICT - From a Transcultural Perspective (EDUHEM), Almeria, Spain. Procedia Social and Behavioral Sciences, Vol. 237 (pp. 242-248).

10. Kumar, H., Singh, M.K., Gupta, M.P. \& Madaan, J. (2020). Moving towards smart cities: Solutions that lead to the Smart City Transformation Framework. Technological Forecasting and Social Change, 153.

11. Lazniewska, E., Janicka, I. \& Gorecki, T. (2021). Green Smart City as a New Paradigm of Local Development. Problemy Ekorozwoju, 16(2), 125-136. 
12. Magaia, N., Fonseca, R., Muhammad, K., Segundo, A.H.F.N., Lira Neto, A.V. \& de Albuquerque, V.H.C. (2021). Industrial Internet-of-Things Security Enhanced with Deep Learning Approaches for Smart Cities. IEEE Internet of Things Journal, 8(8), 6393-6405.

13. Sarv, L. \& Soe, R.M. (2021). Transition towards Smart City: The Case of Tallinn. Sustainability, 13, 4143.

14. Smart Cities and Inclusive Growth. (2020). Organisation for Economic Co-operation and Development. Retrieved from: http://www.oecd.org/cfe/cities/OECD_Policy_ Paper_Smart_Cities_and_Inclusive_Growth.pdf.

15. Song, T., Cai, J.M., Chahine, T. \& Li, L. (2021). Towards Smart Cities by Internet of Things (IoT)-a Silent Revolution in China. Journal of the Knowledge Economy, 12(2), 578-594.

16. Stofkova Z, \& Sukalova V. (2020). Sustainable Development of Human Resources in Globalization Period. Sustainability, 12(18), 7681.

17. Stofkova, J., Stofkova, Z. \& Stofko, S. (2016). Increasing the quality of the educational process through implementation of practice requirements in the university study program. 8th International Conference on Education and New Learning Technologies, Barcelona, Spain, EDULEARN Proceedings, (pp. 1548-1554).

18. Tomsik, R. (2017). Kvantitativny výskum v pedagogických vedách [Quantitative research in pedagogical sciences]. Constantine the Philosopher University in Nitra.

19. Tran, T.J., Helmus, M.R. \& Behm, J.E. (2020). G reen infrastructure space and traits (GIST) model: Integrating green infrastructure spatial placement and plant traits to maximize multifuncionality. Urban Forestry \& Urban Greening, 49.

20. What is a Smart City? - Definition and examples. TWI Global. Retrieved from: https://www.twi-global.com/technical-knowledge/faqs/what-is-a-smart-city.

21. Yang, J., Kwon, Y. \& Kim, D. (2021). Regional Smart City Development Focus: The South Korean National Strategic Smart City Program. IEEE ACCESS, 9, 7193-7210.

22. Zhang, X.D., Manogaran, G., \& Muthu, B. (2021). IoT enabled integrated system for green energy into smart cities. Sustainable Energy Technologies and Assessments, 46. 